\title{
MATERIALIDADE HISTÓRICA, EDUCAÇÃO AMBIENTAL E CIDADANIA: BASES PARA A SUSTENTABILIDADE AMBIENTAL
}

\author{
Ivan Ronaldo de Almeida Pessanha ${ }^{1}$ \\ Denise Celeste Godoy de Andrade Rodrigues ${ }^{2}$ \\ Marcelo Paraíso Alves ${ }^{3}$
}

Resumo: Há muito se discute sobre a relação que o ser humano desenvolve com o meio ambiente que o cerca em sua evolução histórica. Com a consolidação do sistema capitalista essa relação passou a ser predatória, especialmente pela incapacidade humana em consorciar seu afã de lucro com o ritmo da Terra de manter o seu equilíbrio natural. A chamada educação tradicional vem contribuindo para a manutenção de paradigmas que vislumbram a promoção socioeconômica, calcadas na capacidade humana de consumo e posse de bens materiais, como meta social. A proposta deste artigo é contribuir para a discussão sobre essa realidade, subsidiando o leitor para que o mesmo possa refletir sobre a correlação existente entre o materialismo histórico marxista, cidadania, trabalho e sustentabilidade ambiental. Este trabalho expõe o resultado de uma pesquisa exploratória, a partir de dados - livros e artigos científicos - publicados sobre a questão ambiental. De forma mais específica, sistematiza e problematiza a discussão envolvendo o trinômio materialismo histórico, macrotendências político-pedagógicas da Educação Ambiental e a organização do ser humano, enquanto cidadão, envolvimento que contribui para a chamada sustentabilidade ambiental.

Palavras-chave: Meio Ambiente; Educação Ambiental; Materialismo Histórico.

${ }^{1}$ Colégio Naval, Angra dos Reis, RJ. E-mail: ivan.pessanha@bol.com.br

${ }^{2}$ Centro Universitário de Volta Redonda, Volta Redonda, RJ. E-mail: denise.cqar@gmail.com

${ }^{3}$ Centro Universitário de Volta Redonda, Volta Redonda, RJ. E-mail: marceloparaiso1@yahoo.com.br 


\section{Introdução}

O ser humano se apropria da natureza através do seu trabalho e esse é fruto de sua evolução histórica e social. Nesse sentido, entender como a sociedade se organiza e constrói essa forma de apropriação é fundamental para compreender a sua articulação enquanto agente transformador sobre o meio ambiente. $O$ processo educativo exerce papel de grande relevância sobre a relação homem-natureza, uma vez que é a partir do conjunto de conhecimentos transmitidos através das gerações, envolvendo os mais variados campos do saber, que o binômio ensino-aprendizagem se faz valer como agente de transformação e emancipação do ser humano. Toda educação carrega consigo o contexto ambiental, pois 0 ato de ensinar relaciona-se com aspectos físicos, sociais, econômicos e políticos, os quais permeiam o cotidiano do ser humano e, como tal, acabam influenciando direta ou indiretamente o meio ambiente.

A educação tradicional acaba reproduzindo os interesses do sistema capitalista, o qual, em sua fase neoliberal, adapta o ser humano ao modelo de organização social previamente estabelecido em função das relações historicamente determinadas por esse mesmo sistema, o qual precisa de uma massa social doutrinada e encaixada num modelo societário consumista e pouco questionador. $O$ educador que segue a chamada pedagogia tradicional torna-se um semeador das ideias de que o conhecimento adquirido durante o processo de aprendizagem e da formação do sujeito deve ser utilizado basicamente para o seu enquadramento junto ao mercado de trabalho e a sua busca por aquisições de bens materiais. Dessa forma, o processo educativo se transforma num dispositivo mantenedor de velhos paradigmas, onde o indivíduo não só segue e reproduz as exigências de um mercado excludente e expropriador, mas passa a ser também minado em sua capacidade dialógica e crítica sobre esse mesmo mercado.

Paulo Freire (2007), em sua educação libertadora, defendia uma linha pedagógica oposta a vertente dita tradicional, onde comungava com a ideia de que o resgate das classes sociais mais pobres, a partir de um processo educativo referenciado pela realidade de suas condições de vida e de suas formações históricas, acabaria por consolidar um caminho transformador e de fundamental importância para a questão da cidadania. Assim, além de fortalecer a organização social dos agentes envolvidos, acabaria por fomentar também o engajamento político dos mesmos na busca de uma sociedade mais justa, rompendo assim com velhos paradigmas. A partir dessa realidade, o processo de cooperação começaria a se tornar mais importante que a competição, especialmente entre os elementos que compõem a base da nossa pirâmide societária, gerando um comprometimento pela busca de um bem-estar voltado ao respeito pelos bens que são de uso e de interesse coletivo. Como apontado por Loureiro (2009, p.87): 
Nesse sentido, a educação libertadora é politicamente transformadora, e é fundamentalmente aí que se confronta com a educação tradicional, que se refere à adaptação do sujeito social ao modelo de organização social pré-estabelecido pelas relações historicamente determinadas.

Segundo Saviani (2005), o trabalho educativo é o ato de produzir, direta e intencionalmente, em cada indivíduo singular, a humanidade que é produzida histórica e coletivamente pelo conjunto dos homens. Dessa forma, percebemos a valorização dos saberes acumulados como proposta pedagógica comprometida com a instrumentalização dos sujeitos para a prática social, entendida como transformadora, a qual contribui para que o indivíduo perceba a importância do coletivo sobre o individual, fundamento ímpar para uma verdadeira proposta ambiental. Sendo assim, resgatar as camadas sociais desassistidas pelos poderes constituídos, onde muitos já não se percebem mais como integrantes dessa sociedade, torna-se fundamental na tentativa de se criar tanto um ideário coletivo de comprometimento, como a de se buscar um modelo societário solidário e comprometido, o qual venha contemplar as necessidades básicas e justas para todos.

A chamada pedagogia histórico-crítica relaciona-se com as relações sociais e com a busca de uma qualidade de vida que venha contribuir com a melhoria das condições de sobrevivência dos seres humanos. Nesse sentido, essa linha pedagógica se esforça em trilhar um caminho em que os integrantes da sociedade tenham não só conhecimento sobre o seu papel dentro do meio que o cerca, mas busquem caminhos que possibilite colocar em prática o exercício da cidadania. Dentro desse propósito, levando em consideração que a natureza resulta de como os seres humanos se relacionam enquanto seres produtivos, anseia-se a partir desta realidade por uma reprodução saudável da vida em sociedade, a qual consolidará o equilíbrio socioambiental.

A crise ambiental atual é analisada por várias vertentes de pensamento. Segundo Layrargues (2011), a sua abordagem filosófica tem na questão cultural o elemento mediador da relação humana com a natureza e, portanto, são os valores culturais que assumem a centralidade da dinâmica pedagógica da Educação Ambiental. O mesmo autor acrescenta um novo viés de pensamento que vem a se somar ao entendimento da crise em questão, ou seja, a sua abordagem sociológica. Nessa vertente, a relação homem-natureza é mediada pelo trabalho e o plano material passa a assumir papel de grande relevância. Dessa forma, a proposta pedagógica tradicional, posta em prática por muitas instituições de ensino, tem de ser repensada, pois a formação do indivíduo não pode ser mais voltada basicamente para um mercado de trabalho que acaba por pregar o individualismo, o consumismo, a competição desenfreada, a concentração de riquezas e a ruptura entre o homem e a natureza. A dita pedagogia crítica volta-se à formação do cidadão para um mercado de trabalho mais solidário, onde o respeito ao próximo passa também pelo bem maior que possuímos: a natureza, de onde extraímos os recursos à nossa sobrevivência. 
A pedagogia crítica para a Educação Ambiental articula a concepção de educação como processo de formação de um ser humano crítico, com uma concepção de ambiente pautado nos aspectos sociais, históricos e políticos, ou seja, um ambiente mais amplo do que se imagina. Assim, percebemos que a linha pedagógica em pauta possui forte vínculo com a cidadania plena, onde a inserção societária do indivíduo não se volta apenas para a aquisição de um conjunto de conhecimentos cognitivos compatíveis às necessidades de mercado, mas vai além. Nesse sentido, Leff (2001, p. 89) afirma que:

(...) o ambiente não é, pois o meio que circunda as espécies e as populações biológicas é uma categoria sociológica (e não biológica), relativa a uma racionalidade social, configurada por comportamentos, valores e saberes, como também novos potenciais produtivos.

A partir dessa realidade, percebe-se que a pedagogia crítica da Educação Ambiental possui um viés de comprometimento com indivíduos ambientalmente responsáveis, onde os compromissos social, político e histórico vislumbram uma sociedade mais justa e sustentável. Essa proposta de educação busca contribuir para a compreensão da realidade e para a transformação, simultânea, da sociedade e da educação, no processo de formação humana (MÉSZAROS, 2005).

Portanto, a adoção de um processo educacional pautado numa metodologia crítica, criativa, participativa, reflexiva e transformadora é condição fundamental para que tenhamos uma sociedade mais justa e consciente, tanto de seus direitos como deveres. Essa relação tende a contribuir de forma contundente para que o ser humano se aproprie dos bens naturais de forma mais racional e menos predatória, passando assim a respeitar os próprios limites da natureza, a qual teria um lastro maior de tempo para a sua própria recomposição.

A partir do exposto será destacada a importância do materialismo histórico marxista, caracterizada pelo movimento de pensamento através da materialidade histórica da vida dos homens em sociedade (PIRES, 1996). Vale destacar que a intenção do presente artigo não é a de enaltecer ou desmerecer qualquer sistema político e econômico, ou ainda, se criar aqui um modelo metodológico padronizado e hermético enquanto solução para a questão ambiental. A ideia é contribuir com algumas perspectivas de entendimentos que possam somar forças para que o leitor perceba algumas das principais causas que vem levando o ser humano a se apropriar do meio ambiente de forma predatória e inconsequente. A partir desse entendimento, onde uma minoria se esquiva de suas responsabilidades e transfere o ônus dessa degradação especialmente aos mais pobres e às nações ditas subdesenvolvidas, ficará mais fácil opinar e se posicionar sobre o tema.

Como dito por Jacobi (2005), as transformações no debate "meio ambiente-desenvolvimento" têm início nos anos 1970. Essa realidade ganha 
maior projeção na medida em que o modelo de produção capitalista passa a ditar paradigmas de produção e consumo que se incompatibilizam com a capacidade da Terra em fornecer recursos naturais para tal. Nesse sentido, várias correntes de entendimentos sobre a questão socioambiental se difundiram mundo a fora, alimentadas por perguntas e respostas que, na maioria das vezes, são balizadas por interesses econômicos manipulados por e para uma minoria. Essa realidade acabou encontrando eco nas instituições de ensino, uma vez que o contexto ambiental, por sua própria gênese, envolve discussões de cunho político, social, econômico e natural, aguçando assim os mais variados campos do saber.

De forma mais objetiva, até pelo fato de que o presente artigo não vislumbra a centralização de um debate em torno das diversas correntes de Educação Ambiental, mas sim destacar algumas das tendências mais discutidas na atualidade, apresentaremos três macrotendências, identificadas e nomeadas por Layrargues e Lima (2011) como Conservacionista, Pragmática e Crítica. Essas macrotendências envolvem linhas de entendimentos que se materializam através da práxis político-pedagógicas junto a Educação Ambiental e, por extensão, disseminadas junto ao contexto societário, uma vez que as instituições de ensino desempenham um papel ímpar na multiplicação de ideias, valores e discussões entre seus pares e estes com suas comunidades.

A macrotendência Conservacionista vislumbra um caminho superficial para o equacionamento dos problemas ambientais, uma vez que se utiliza de práticas que não contemplam efetivamente entendimentos e soluções às causas estruturais que levam aos impactos causados ao meio ambiente e sua possível degradação. Essa macrotendência, que possui alinhamento conceitual com a chamada corrente naturalista, busca um entendimento calcado em princípios naturalistas, conhecido também por "pauta verde", apoiando-se nos fundamentos científicos e princípios filosóficos da ecologia, a exemplo da Biomimetismo (Benyus, 1997). Empenha-se em difundir a afetividade junto à natureza como princípio básico para a sua manutenção, onde o indivíduo deve passar por uma alfabetização ecológica para aprender a respeitar a natureza, colocando em prática atividades como ecoturismo, trilhas interpretativas, escotismo etc. Como apontado por Layrargues (2012), mantém relação com filosofia da natureza, ecologia profunda, e eco-espiritualidade. Ainda sobre essa corrente, nos orienta Sauvé (2005, p. 19):

A tradição da corrente naturalista é certamente muito antiga, se considera-mos as "lições de coisas" ou aprendizagem por imersão e imitação nos grupos sociais cuja cultura está estreitamente forjada na relação com o meio natural. No curso do último século, a corrente naturalista pode ser associada mais especificamente ao movimento de "educação para o meio natural" e a certas proposições de "educação ao ar livre".

A macrotendência Pragmática, na verdade uma adaptação da tendência Conservacionista ao contexto econômico atual, onde tudo deve se transformar Revbea, São Paulo, V.11, № 2: 216-239, 2016. 
em capital e de forma mais dinâmica possível, incorpora o meio ambiente aos preceitos capitalistas de forma mais efetiva, uma vez que transforma os problemas ambientais em oportunidades econômicas. Essa tendência alinha-se com as vertentes da educação para o desenvolvimento e o consumo sustentável. Nesse particular, observamos que os problemas ambientais tornamse um instrumento de posse do capital que, por sua vez, se utiliza dos centros acadêmicos para difundirem conceitos e práticas que se tornam paliativos para um verdadeiro equacionamento sobre a realidade envolvendo meio o ambiente $e$ sua degradação. Nesse tocante, a macrotendência em questão, segundo Layrargues (2012, p. 403):

(...); responde à "pauta marrom" por ser urbano-industrial, antes focada no lixo, coleta seletiva e reciclagem dos resíduos, se amplia na virada do século para o Consumo Sustentável e atualmente converge com temas da Mudança Climática e da Economia Verde. Apoia-se nas tecnologias limpas, ecoeficiência empresarial, sistemas de gestão ambiental, criação de mercados verdes (como o mercado de carbono), serviços ecossistêmicos, racionalização do padrão de consumo, impacto zero, criação de indicadores de sustentabilidade (como a "pegada ecológica"), entre outros.

Fato interessante é que a macrotendência Pragmática procura difundir a ideia de que cada um deve fazer a sua parte, quase que de forma isolada, afastando assim o indivíduo de suas participações no modelo societário inserido, o que acaba por desconstruir o tecido social, uma vez que as comunidades só existem enquanto coletivo. O slogan "cada um faz a sua parte" que "o meio ambiente agradece" é o centro dessa narrativa (LAYRARGUES, 2012), o que contribui para a propagação de pensamentos do tipo "estou fazendo a minha parte e não estou nem aí para os outros". Dessa forma, semeia-se uma ideologia perversa, a qual isola o ser humano enquanto força social, capaz de se organizar e lutar por uma verdadeira bandeira ecológica, a qual se paute em ações antecedidas por reflexões.

A chamada macrotendência Crítica, com alinhamento conceitual e epistemológico com o que Tozoni-Reis (2004) define como Histórica e que Martinez-Alier (2007) chama de "ecologismo dos pobres", é aquela que entendemos como sendo a que mais se aproxima de um processo de Educação Ambiental dita emancipatória e transformadora. Essa macrotendência, como enfatizado por Layrargues (2012), se declara explicitamente pertencendo a uma filiação político-pedagógica. Por tanto, percebemos que essa linha de entendimento busca na discussão dialética, na participação coletiva e no senso crítico, suas bases reflexivas que culminem em ações coerentes para se equacionar a problemática ambiental atual. Essa macrotendência, por ser a linha norteadora do entendimento socioambiental nesse trabalho, acabará sendo discutida ao logo desse artigo. 


\section{O materialismo histórico dialético}

A Segunda Guerra Mundial (1939-1945) provocou grandes perdas humanas, materiais e econômicas no cenário global, no entanto, entre a década de 1950 e começo dos anos 1970 ocorreu uma recuperação econômica surpreendente das áreas ditas centrais ou ricas do planeta, tanto de cunho socialista como, especialmente, capitalista, já que o pós-guerra, em função da Guerra Fria (1947-1989), estimulou a necessidade de reconstrução não só desses países como também daqueles ditos periféricos ou pobres. Essa realidade demandou enormes ofertas de energia e de matérias-primas, desencadeando assim uma apropriação dos recursos naturais da Terra como nunca visto, pois o consumo passou a ser associado com progresso, bem-estar socioeconômico, além de ótima propaganda numa época de disputa por espaços entre capitalismo e socialismo.

Estimuladas pelas transnacionais, fiéis representantes do poder econômico das nações desenvolvidas e contando sempre com o suporte da mídia, tais nações acabaram ampliando seus raios de poder sobre diversos continentes, mas também acabaram ditando gradativamente as regras de produção e de consumo no cenário internacional. Os Estados Unidos da América do Norte, nesse particular, assumiram papel destacado, não só pelo fato de terem mantidos intactos os seus parques industriais, uma vez que a Segunda Guerra Mundial teve como grande palco a Europa, mas também pela difusão do seu American way of life, o qual seria seguido por diversas nações do globo. Segundo Hobsbawn (2012), esse período foi considerado a Era de Ouro.

A retomada do crescimento econômico mundial impulsionou os gastos com as mais variadas áreas econômicas, período em que se presenciou também um gigantesco aumento de investimentos nos setores ligados a defesa, especialmente das ditas grandes potências. Essa realidade acabou por impulsionar diversos segmentos produtivos, revitalizando-se toda a cadeia produtiva, desde as ditas indústrias pesadas até as de bens de consumo. A produção mundial de manufaturas quadruplicou entre o início da década de 1950 e o início da década de 1970 e, o que é ainda mais impressionante, o comércio mundial de produtos manufaturados aumentou dez vezes (WORLD RESOURCES, 1986, pp. 47 e 142).

Por conta disso, o mercado global acabou assistindo uma febre de consumismo sem precedentes, no entanto, ainda que também viessem a perceber posteriormente vários colapsos na pujante economia de mercado, a ideologia do consumo já havia sido semeada e enraizada nas mais variadas sociedades. Isso fez surgir vários questionamentos sobre a forma como o ser humano passou a tratar o meio ambiente, produto da manutenção de um mercado extremamente excludente e predatório. No entanto, para muitos, acreditar que o acesso a bens materiais, aliados aos confortos oferecidos pelo desenvolvimento tecnológico, passou a ser capaz de compensar a degradação ambiental, fato reforçado pela ideia que o homem atual já não consegue mais enxergar-se como elemento da natureza.

Revbea, São Paulo, V.11, № 2: 216-239, 2016. 
O fim da guerra fria mostrou que o capitalismo seria o grande vitorioso em todos os sentidos no embate com o socialismo, uma vez que a liberdade, a democracia e a posse de bens materiais seriam típicas daquele sistema, onde sua acessibilidade seria comum a todos, e utópicas nesse. No entanto, analisando com mais atenção, percebemos que o ser humano nas últimas décadas está perdendo o censo da cooperação em detrimento da competição, típico de um sistema onde a busca do bem estar individual está suprimindo o coletivo, já que por excelência é um sistema excludente e concentrador da riqueza. Segundo Leroy e Pacheco (2011, p. 66):

A democracia é a busca e a construção permanente de acordos, através da negociação, e a gestão democrática dos dissensos, de forma a assegurar a possibilidade de convivência entre classes e setores sociais e a execução de políticas que permitem a todos viver com dignidade.

O ser humano que despontou no século XXI passou a vislumbrar a necessidade de um engajamento mais contundente sobre tudo o que o cerca, seja no âmbito econômico, social, político e ambiental. Essa necessidade tornouse mais aguda e explícita pela aproximação dos povos e dos contatos entre os mesmos, tanto pelos meios de transportes como o de comunicações, destacando-se nesse campo a informática, os quais tornaram mais fáceis as discussões em tempo real sobre os mais variados problemas e preocupações que afetam a humanidade. Isso possibilitou reforçar e trazer à tona a questão ambiental, pois se o sistema capitalista com a oferta de bens materiais propiciou certo bem estar ao ser humano, a cobrança que a Terra nos impelirá será alta, especialmente para as futuras gerações, pois a atual parece estar tentando se esquivar de suas responsabilidades. Como nos aponta Layrargues (2011, p. 72):

Com efeito, não seria exagero afirmar que o século XXI se inicia com uma vigorosa ideia-força que advoga a imperativa necessidade do estabelecimento de uma nova relação entre humanos e natureza, para reverter o controverso, mas provável quadro de degradação ambiental global, inclusive onde o próprio capitalismo encontra-se sob suspeita, apontado por muitos como um fator decisivo da degradação ambiental.

Muitos questionamentos acabam surgindo em função da correlação existente entre capacidade tecnológica e degradação ambiental, ou seja, de que o ser humano com suas inovações tecnocientíficas poderia continuar explorando o meio ambiente e minimizando, ou até mesmo erradicando, os ditos impactos ambientais. No entanto, deve-se ressaltar que o sistema capitalista vigente, o qual rege a dinâmica socioeconômica da maioria dos povos, traz em seu bojo o ditame do excedente de produção, a exploração da força de trabalho e a alienação do trabalhador. Segundo Trein (2012), tal realidade reforçou a mercantilização tanto dos bens naturais quanto do trabalho humano, ou seja, 
concentrou o lucro. Isso contribui não só para minar a formação plena da cidadania, mas também a degradação do meio ambiente numa velocidade superior a sua própria capacidade de recomposição. Assim, além de acelerar a erradicação dos recursos não renováveis, acabaria por privar as futuras gerações de bens naturais que poderiam lhes garantir condições satisfatórias à sua sobrevivência.

A forma como a maioria das sociedades se relaciona com o meio ambiente acaba por distanciá-las das questões ambientais, uma vez que as mesmas passam a encarar o meio natural como um espaço distante e desconectado de si e, como tal, já não se vendo mais integrante do mesmo. Nesse sentido nos alerta Lima (2009), quando diz que os seres humanos retiram-se da natureza. Eles olham a natureza como quem olha uma fotografia. Assim sendo, esse dito meio natural se tornou algo distante do homem e transformou-se numa dispensa, onde existem mercadorias sempre à disposição e que podem ser repostas mediante a capacidade tecnológica e ao seu poder aquisitivo. Esses fatos colaboram para que a humanidade venha repensar esse modelo de apropriação não só dos recursos naturais, mas da própria relação social vigente, a qual, em seu processo predatório instalado, garante o lucro e o bem-estar de uma minoria em detrimento do prejuízo e da degradação socioeconômica da maioria.

Karl Marx, alemão, economista e filósofo, que viveu no século XIX, na tentativa de encontrar um caminho que o respaldasse sobre o conhecimento para a interpretação do momento histórico e social que o desafiava em sua época, aglutinou à dialética de até então, muito voltada ao campo filosófico, um caráter materialista e histórico. Isso se tornou importante num momento em que a Europa passava pelo fortalecimento da chamada Revolução Industrial, aonde a exploração dos recursos naturais e da força de trabalho chegava a patamares como nunca visto.

Nesse processo, em função do ritmo exploratório e da pauperização humana, o trabalhador além de perder a capacidade de entendimento sobre a relação de forças que estariam regendo as relações de trabalho, passou a se distanciar da própria natureza, se tornando então apenas uma mera peça de uma engrenagem desconhecida. Segundo Marx (1981), uma vez alcançado certo nível de desenvolvimento, a apropriação privada da natureza se manifesta como supérflua e nociva. Nesse sentido, o trabalhador tenderia a se tornar apenas uma peça ou parte dessa grande engrenagem, o qual seria substituído na medida em que já não pudesse oferecer lucro, sendo por isso simplesmente descartado do sistema produtivo.

O caráter materialista marxista diz respeito à organização e a intencionalidade da sociedade para a produção e a reprodução de sua sobrevivência, especialmente através das relações de trabalho. Como dito por Trein (2012), os homens satisfazem as suas necessidades através de uma atividade intencional, ou seja, a intenção precede sua realização. Já o caráter histórico busca compreender como essa sociedade se organiza através de sua formação em seu percurso histórico, ou seja, procura desvendar para interpretar Revbea, São Paulo, V.11, № 2: 216-239, 2016. 
a realidade, as formas históricas das relações sociais estabelecidas pela humanidade, as quais moldam a forma como o ser humano executa suas atividades produtivas, as quais são postas em prática junto ao meio que o cerca. Nesse sentido nos aponta Pires (1997, p. 85):

Para o pensamento marxista, importa descobrir as leis dos fenômenos de cuja investigação se ocupa; o que importa é captar, detalhadamente, as articulações dos problemas em estudo, analisar as evoluções, rastrear as conexões sobre os fenômenos que os envolvem.

Em outras palavras, o ser humano se apropria da natureza em função do seu trabalho e esse é fruto de sua formação histórica. Essa formação resulta de uma conjuntura social, econômica e política, a qual o molda suas ações e sua relação com o meio que o circunda. Dessa forma seria imprescindível nos ater a um processo educacional revigorante, o qual seja o pivô para uma nova forma de construção ética do ser humano, onde a verdadeira cidadania seja uma busca constante pautada na força do e pelo coletivo, exatamente para não se ficar refém de um sistema aonde o lucro fácil de uma minoria consiga desestruturar o bem-estar da maioria. A evolução tecnocientífica forneceu ao ser humano a capacidade de transformar a natureza em inúmeras possibilidades de sobrevivência, ampliando relativamente o seu tempo para outras atividades, ao mesmo tempo em que se passa perceber cada vez menos natureza e cada vez mais cultura. Nesse particular, Marx (2010, p. 84) diz:

A natureza é o corpo inorgânico do homem. O homem vive da natureza, ou também, a natureza é o seu corpo, com o qual tem de manter-se em permanente intercâmbio para não morrer. Afirmar que a vida física e espiritual do homem e a natureza são interdependentes significa apenas que a natureza se interrelaciona consigo mesma, já que o homem é uma parte da natureza.

A dialética, enquanto instrumento do pensamento humano, não é algo novo, possuindo relatos de sua prática já na antiguidade. Segundo Pires (1997), ainda na Grécia antiga, a dialética era muito comum, sendo entendida como a arte do diálogo. Sua essência parte do princípio que a busca da verdade surge através da conversa, principalmente entre atores que divergem sobre um determinado assunto e que normalmente se respeitam mutuamente. No entanto, com Marx, esse pensamento ganhou novas dimensões, pois além de extrapolar o campo meramente filosófico, conferiu-lhe um caráter material, onde as relações de trabalho, fruto das relações históricas da sociedade, ocupariam papel de grande relevância. Isso possibilitou a tentativa de se abreviar a distância entre sujeito e objeto no processo de formação histórico-social do indivíduo dentro de sua comunidade. As divergências de pensamentos se tornam assim um terreno fértil para que novas ideias surjam e possam colaborar 
para soluções dos mais variados problemas, pois a consciência de que fazemos parte de um todo se torna importante para a prática de atividades coletivas em busca de um mundo melhor para todos.

Partindo dessa realidade dialética de Marx, entende-se que o ser humano é um fio importantíssimo na grande teia da natureza, possuindo por isso grande responsabilidade em sua manutenção. Interage direta ou indiretamente com o meio ambiente, retira dele seu sustento e satisfação socioeconômica a partir do seu trabalho. Portanto, resgatar o homem enquanto ser sociável e permitir-lhe 0 acesso ao debate e a participação junto aos processos de mudanças a que a sociedade necessita é condição fundamental para se alcançar soluções que venham contribuir para um equacionamento democrático, plural, participativo, crítico e criativo junto ao contexto ambiental, condição vital para o equilíbrio do sistema. A partir desse entendimento, a educação adquire papel imprescindível, especialmente pelo fato da mesma exigir discussões cotidianas acerca dos paradigmas concernentes à sua prática. Essa questão ganha força na medida em que a relação sujeito-objeto torna-se questão central em discussões que visem uma convivência harmoniosa com o meio ambiente. Conforme exposto por Loureiro e Viégas (2012, p. 17):

A práxis na tradição marxista pode ser entendida como atividade intencionada intersubjetiva que revela o humano como ser criativo, social, e autoprodutivo - ser que é produto e criação de sua atividade no mundo e em sociedade. É ato, ação e interação.

Na relação homem-natureza a dialética ganha destaque, uma vez que o ser humano em sua formação histórica acabou estabelecendo uma relação de diálogo com a natureza onde somente ele fala, ordena e estabelece normas como sendo verdades absolutas; valendo frisar que estas normas são estabelecidas por uma elite, que além de criar paradigmas ambientais, se apropria dos lucros e tenta socializar os prejuízos. Dialogar com "os diferentes", aqui entendidos com aquela parcela da sociedade que discorda desses modelos de relação homem-natureza e que por isso normalmente acaba sendo excluída, se torna fundamental para encontrarmos um caminho mais racional para a questão ambiental atual. Como nos diz Novelli e Pires (1996), não é a concórdia que conduz ao diálogo, mas a divergência, isto é, a exacerbação do conflito.

O ser humano no atual estágio mercantilista em que se encontra acaba sendo movido pela busca da satisfação financeira. Gostaria que isso fosse uma realidade distante, no entanto, seria hipocrisia pensar o contrário. As gerações que se formam são induzidas a buscarem o caminho da felicidade através do acúmulo material e econômico, onde o instinto natural de sobrevivência passa a ser forjado na tempera de um capitalismo que precisa isolar o indivíduo para evitar questionamentos e, assim, facilitar a sua dominação. Nesse sentido, resgatar a aproximação e o diálogo entre aqueles que compõem uma comunidade é condição ímpar para se iniciar um processo de reestruturação 
social pautada na troca de ideias que venham beneficiar a maioria em detrimento de uma minoria extremamente concentradora da riqueza e do direito de opinar sobre aquilo que acaba afetando a todos.

\section{A Educação Ambiental}

Segundo a Lei de Diretrizes e Bases da Educação Nacional (Lei nº 9.394 de 20.12.96), a educação abrange os processos formativos que se desenvolvem na vida familiar, na convivência humana, no trabalho, nas instituições de ensino e pesquisa, nos movimentos sociais e organizações da sociedade civil e nas manifestações culturais. O conceito de educação em questão, aceito e utilizado por muitos para balizar a prática da docência, acaba se afastando de sua essência na medida em que teoria e prática se distanciam, já que a ação docente acaba sofrendo inúmeras influências, tanto de cunho político, econômico e de classes sociais.

A prática da Educação Ambiental, muito influenciada por elementos de ordem física, política, econômica e social, acaba por imputar a necessidade de uma relação enjangada com o envolvimento e o conhecimento dessas questões no seu dia a dia, exatamente para se romper com paradigmas que dificultam 0 entendimento entre o real e a aparência. Isso se torna fundamental para que os agentes envolvidos na relação ensino-aprendizagem deixem de serem meros espectadores e se transformem em agentes transformadores na busca do bemestar coletivo. A busca do diálogo, de discussões, do entendimento, da participação e de possíveis soluções para os problemas ambientais, que é coletivo e que crescem a cada dia em todas as comunidades, principalmente pela falta de conhecimentos, se tornam questões fundamentais para a prática de uma verdadeira Educação Ambiental. Nesse contexto, como observado por Marx e Engels (2009, p. 89):

Cabe, portanto, à educação explicitar a articulação entre a produção da vida real (essência) - trabalho alienado, autoritarismo, falsa consciência ambiental - e a vida comum (aparência).

Marx afirma que o ser humano deve ser reinserido no ambiente ao ponto de se sentir humanamente natural ou naturalmente humano (Marx, 2004). Isso se torna fundamental para que o mesmo passe a olhar para a natureza como uma extensão natural do seu corpo e de sua própria existência. Partindo da premissa que tudo relacionado às necessidades primárias de sobrevivência passa pelo acesso aos bens naturais e a sua apropriação resulta do seu desenvolvimento histórico-social, desenvolver e estimular uma Educação Ambiental participativa, dialógica, coletiva, crítica e criativa torna-se um caminho estimulante e promissor para que as sociedades percebam que a Educação Ambiental é uma prerrogativa contributiva e fundamental para a sobrevivência da humanidade. No entanto, para tal, algumas amarras têm de ser desfeitas e 
nesse caso a educação poderá ser utilizada como elemento norteador. Como apontado por Loureiro (2011, p. 73):

A Educação Ambiental é uma práxis educativa e social que tem por finalidade a construção de valores, conceitos, habilidades e atitudes que possibilitem o entendimento da realidade de vida e a atuação lúcida e responsável de atores sociais individuais e coletivos no ambiente. Nesse sentido, contribui para a tentativa de implementação de um padrão civilizacional e societário distinto do vigente, pautado numa nova ética da relação sociedade-natureza.

Por possuir um caráter integrador, já que pode ser trabalhada por diversas disciplinas, a Educação Ambiental desempenha um papel ímpar junto à relação ensino-aprendizagem. A sua prática pode levar o aluno a não só refletir o seu papel dentro de sua sociedade como buscar, em comunhão com seus pares, através do diálogo e das diversas interpretações sobre aquilo que seria um mundo melhor, soluções que contribuam para que as gerações futuras se sintam estimuladas em deixar um planeta melhor para os seus dessedentes. Nesse sentido, na busca de um bem-estar coletivo, perceber a sua força nesse processo seria condição fundamental para a interpretação e a transformação dos modelos existentes em relação ao binômio homem-natureza. Como apontado por Layrargues (2011), o "eu não vou degradar o ambiente" deve ser convertido em "nós não vamos deixar que degradem o meio ambiente".

O sistema econômico vigente estimula 0 ato desenfreado de consumir além das necessidades básicas, o que em tese contribui para que o ser humano alcance diferenciação e destaque nesse modelo societário, já que "o consumo, logo existo" parece ser sempre a ordem do dia. Isso acaba por reforçar velhos modelos, contribuindo para que algumas pessoas não percebam a sua importância no processo de mudanças em busca por soluções junto à crise ambiental vigente. Isso ocorre, em grande parte, pelo fato de acreditarem que consumindo já estariam fazendo a sua parte nesse contexto, já que a sua responsabilidade estaria vinculada ao fato de consumirem, estimulando assim a ciranda econômica e o poder do Estado, legitimando-o como o único responsável a apresentar soluções para a problemática ambiental. No entanto, já percebemos mudanças sobre essa realidade, pois como observado por Guimarães (2011, p. 22):

A partir da argumentação de que a atual crise ambiental é consequência da crise do modelo de sociedade moderna e de seus paradigmas, associada ao reconhecimento que temos hoje na sociedade sobre a gravidade dos problemas ambientais, poderíamos projetar que há um anseio social por transformações da realidade socioambiental. Talvez ainda seja uma afirmativa forte para a sociedade em geral, mas no meio educacional já me 
parece que esse cenário começa a despontar - o anseio por mudanças nessa realidade em crise.

Em termos genéricos e conceituais, a educação é essencialmente política, pois político é o espaço de atuação humana em que nos formamos e moldamos as características objetivas que nos cercam (DEMO, 1988). Nesse sentido, o processo educativo traz consigo a necessidade da discussão, da participação, da crítica e do engajamento criativo daqueles envolvidos no processo ensinoaprendizagem. A questão ambiental, ao longo dos tempos, acabou ficando sob a tutela administrativa dos poderes oficiais constituídos e/ou de grandes corporações transnacionais, afastando assim esse tema dos debates que envolvam a participação das mais variadas instâncias sociais. Nessa questão merece destaque o dito cidadão comum, aquele que normalmente mais sofre com as agressões acometidas ao meio ambiente, uma vez que normalmente não dispõem de instrumentos que lhes permitam minimizar essa realidade.

A linha pedagógica entendida como crítica, envolvida com o exercício da cidadania, procura somar forças para que o cidadão se perceba efetivamente tanto como integrante societário como agente responsável por um bem-estar coletivo. Assim sendo, a Educação Ambiental por reunir uma polivalência de temas condizentes à formação histórico-social dos sujeitos, quando trabalhados de forma coerente e voltados à realidade dos elementos envolvidos, contribui efetivamente para o exercício da cidadania. Como apontado por Jacobi (2003), a cidadania tem a ver com a identidade e o pertencimento a uma coletividade. Isso acaba por criar um comprometimento em prol do próximo e a busca por um modelo societário em que o altruísmo se torne a base de um convívio que objetive um novo pensar ambiental, o qual se materialize a nível local e ganhe forças para se propagar no âmbito planetário. O mesmo autor supracitado (2003, p. 198) nos alerta:

A Educação Ambiental como formação e exercício de cidadania refere-se a uma nova forma de encarar a relação do homem com a natureza, baseada numa nova ética, que pressupõem outros valores morais e uma forma diferente de ver o mundo e os homens.

Mediante o exposto, destacamos que a educação deva exercer um papel que transcenda a mera formalidade de repassar conhecimentos àqueles que estejam compondo uma relação de ensino-aprendizagem, ou seja, a educação tem de estimular um processo que culmine com a participação e a transformação do sujeito, especialmente num cidadão consciente, crítico e ávido por uma necessidade constante de dialogar e aprimorar o seu pensar em prol do coletivo, pois a felicidade só é verdadeiramente plena quando compartilhada. Como dito por Layrargues (2013), a mudança social deve funcionar como um novo paradigma para a Educação Ambiental, a qual deva assumir a articulação com o compromisso social. Assim, enquanto a questão ambiental figurar como algo meramente filosófico e desarticulado do contexto social, sem uma

revista brasileira educação ambiental 
materialidade prática que resulte efetivamente no bem-estar de todos e não mais sendo um artifício utilizado por uma minoria que detém o poder em causa própria, o planeta continuará correndo sérios riscos.

A necessidade de mudanças é urgente, pois do contrário continuaremos a reproduzir uma relação nefasta com a natureza e o que é pior: estaremos negando para a maioria de nossos descendentes uma série de acessos e direitos básicos à sobrevivência. Nessa vertente de entendimento, tendo a pedagogia crítica como pressuposto fundamental para o rompimento com velhos paradigmas ambientais, vislumbramos a sua correlação com a macrotendência ambiental crítica. Consideramos essa articulação como sendo a mais viável para o equacionamento envolvendo a relação entre o ser humano, o meio ambiente e sua resultante, ou seja, a sustentabilidade ambiental. Essa tendência, também denominada de contra hegemônica, se identifica claramente como pertencente a um viés político-pedagógico alinhado com a Educação Ambiental Popular e Emancipatória. Como nos aponta Layrargues (2012, p. 404):

Construída em oposição às vertentes conservadoras no início dos anos 90, é resultado da insatisfação com o predomínio de práticas educativas sempre pautadas por intencionalidades pedagógicas reducionistas, que investiam apenas em crianças nas escolas, em ações individuais e comportamentais no âmbito doméstico e privado, de forma a-histórica, apolítica, conteudística, instrumental e normativa. Se nutre do pensamento Freireano, Educação Popular, Teoria Crítica, Marxismo e Ecologia Política.

Por entender que a macrotendência crítica busca nas relações sociais as verdadeiras causas que orientam o ser humano a se apropriar dos recursos naturais existentes, e que tais relações geralmente refletem os interesses de uma minoria, nada mais sensato do que resgatar e inserir o contingente societário que há muito se encontra a margem de tais interesses. Pois como apontado por Lima (1997), os analistas da problemática ambiental têm reconhecido que pobreza e ecologia são realidades interdependentes, as quais precisam ser compreendidas e abordadas de forma integrada. Nesse particular, destacamos Sauvé (2005, p. 30):

Esta corrente insiste, essencialmente, na análise das dinâmicas sociais que se encontram na base das realidades e problemáticas ambientais: análises de intenções, de posições, de argumentos, de valores explícitos e implícitos, de decisões e de ações dos diferentes protagonistas de uma situação. Esta postura crítica, com um componente necessariamente político, aponta para a transformação de realidades. Não se trata de uma crítica estéril. Da pesquisa ou no curso dela emergem projetos de ação em uma perspectiva de emancipação, de libertação das alienações. 
Nesse sentido, partindo do pressuposto que a sociedade só existe a partir do e para o coletivo, dinamizada por discussões, contrariedades de pensamentos, consentimentos e participações ativas, torna-se imprescindível a prática crítica sobre todas as ações que digam respeito ao bem-estar social dos elementos envolvidos.

\section{O Desenvolvimento Sustentável}

A ecologia é uma ciência da natureza. Seu objeto é o estudo das relações entre os seres vivos e o meio onde vivem. Essa ciência procura contribuir para que o ser humano, de forma racional e equilibrada, se aproprie dos recursos naturais não apenas para suas necessidades imediatas, mas também para as gerações futuras, num processo em que a Terra tenha uma maior capacidade de se recompor mediante tal apropriação. Para tanto, se utiliza de discussões que envolvam questões científicas, as quais venham sustentar seus argumentos, tais como: poluição, aquecimento global, transgênico etc. Conforme apontado por Cise (2008), num outro polo de entendimento sobre as questões ambientais surge o chamado ecologismo, linha de entendimento que diverge da ecologia enquanto ciência.

O ecologismo se transformou num instrumento em que a questão ambiental é vista e analisada de forma descontextualizada dos elementos sociais, econômicos, políticos e naturais. Essa linha de entendimento sobre a realidade ambiental acabou sendo apoderada tanto por instituições oficiais, geridas pelo Estado e/ou pelo grande capital. A intenção é se utilizar do filão ambiental premeditando continuar reproduzindo os seus lucros, privatizando os dividendos e repartindo os prejuízos, especialmente com os menos desprovidos. Essa camada social, além de compor a maioria do contingente planetário possui também uma reduzida ou, em alguns casos, nenhuma forma de organização, o que favorece 0 surgimento de velhos modelos e conceitos arbitrários extremamente excludentes e concentradores de riquezas. Como alardeado por Sachs (2010, p. 135):

Os $20 \%$ mais ricos se apropriam de $82,7 \%$ da renda. Como ordem de grandeza, os dois terços mais pobres têm acesso a apenas $6 \%$. A concentração de renda é absolutamente escandalosa e nos obriga a ver de frente tanto o problema ético, da injustiça e dos dramas de bilhões de pessoas (...) Não haverá tranquilidade no planeta enquanto a economia for organizada em função de um terço da população mundial.

Dessa forma, enquanto a realidade ambiental não for encarada como sendo produto de uma relação macro, onde várias variáveis devem ser analisadas conjuntamente, essa questão ficará reduzida a algo local e vista como um fato natural. Poluição, degradação de cursos hídricos, florestas, oceanos etc. serão encarados como um ônus normal para uma sociedade que 
busca o desenvolvimento econômico e, para alguns, sustentável. Portanto, se tornou urgente um novo pensar sobre a questão ambiental e o chamado desenvolvimento sustentável.

Em 1972 ocorreu a primeira Conferência Mundial Sobre Meio Ambiente das Nações Unidos, na Suécia. Essa conferência ocorreu pela necessidade de se reavaliar a crescente relação entre crescimento demográfico, econômico e a demanda por recursos naturais a nível global, especialmente junto aos países mais pobres, que por somarem a grande fatia populacional do planeta, passariam a interferir no padrão de consumo das nações mais ricas. Em 19 de outubro de 1987, as bolsas de valores asiáticas abriram de forma desastrosa e isso se espalhou pelo mundo, gerando grandes perdas econômicas.

Segundo a revista eletrônica Infomoney (2009), o grande destaque ficou para a variação do índice acionário norte-americano Dow Jones, que despencou $22,6 \%$ naquele dia. Soma-se a isso o fato de que mais tarde a década de 1990 assinalaria a materialização da globalização econômica, respaldada pela difusão de um neoliberalismo ferrenho e o desmantelamento do estado em diversas nações, especialmente nos países mais pobres. Nesse contexto, o grande capital enxergou na questão ambiental, leia-se recursos naturais e sua acessibilidade, uma forma de manter o seu afã de lucro em momentos de crise, no entanto, para tal, teria de articular todo um conjunto ideológico que the abrisse caminho nesse sentido.

Em 1987 foi publicado o chamado Relatório Brundtland, fruto da Comissão Mundial de Meio Ambiente e Desenvolvimento, criada pela ONU (Organização das Nações Unidas) e presidida pela norueguesa Grö Harlem Brundtland. Esse relatório seria reconhecido como o fundador do conceito de desenvolvimento sustentável, criado e estimulado pelas nações mais ricas e desenvolvidas, as quais passariam a difundirem a ideia que tal desenvolvimento seria possível não só com a ajuda de todos, mas estendidos a todos, desde que a natureza fosse respeitada. Isso é muito interessante, especialmente quando sabemos que o capitalismo é um sistema com distinção clara de classes sociais, onde uma minoria se sobressai perante a maioria. Ainda apontado por Cise (2008, p. 25):

Quando o Relatório Brundtland surgiu, o caráter decomposto do regime da propriedade privada dos meios de produção era realidade há muito tempo. Os povos dos países dominados, esmagados por uma dívida que não era sua, sofriam as consequências terríveis das políticas de ajuste estrutural impostas pelo FMI e o Banco Mundial. Ao mesmo tempo, o capital financeiro tirava dessa destruição novas oportunidades de lucros.

Para as nações mais pobres, muitas das quais concentram boa parte dos recursos naturais preservados do planeta, não restou praticamente alternativa a não ser a de permitirem à exploração desses recursos, geralmente feitos pelas grandes transnacionais ligadas as atividades de mineração e agropecuária. Tais 
permissões normalmente se originam de pressões políticas e econômicas comandadas por gigantescas corporações financeiras ou instituições como são os casos do FMI (Fundo Monetário Internacional) e do BIRD (Banco Internacional para a Reconstrução e Desenvolvimento), mais conhecido como Banco Mundial. Ambas são comandadas pelo G-7 (grupo dos sete países mais ricos do planeta) e ligados a ONU (Organização das Nações Unidas), instituição criada no pós Segunda Guerra Mundial e com diversos objetivos, dentre os quais a de promover a qualidade de vida em todo o planeta.

Há muito o ser humano se depara com uma apropriação dos bens naturais do planeta em escala exponencial, pois a essência da economia de mercado é pautada no consumo e estímulo para isso não falta, especialmente pelo fato da mídia, a serviço de corporações cada vez mais ávidas por lucros, cria mecanismos cada vez mais sofisticados para que o povo se veja como integrante de sua comunidade a partir de sua capacidade de consumir. Essa realidade ganhou maior projeção a partir da retomada do crescimento econômico global, nos anos 1950; no entanto, como já mencionado, nas décadas de 1980 e 1990 esse crescimento começou a gerar inúmeros problemas, ao ponto do capitalismo ser obrigado a se reinventar para continuar sua escalada de acumulação de riquezas. Essa proposta de bem-estar socioeconômico, criada e difundida por um sistema imediatista e que só vislumbra a acumulação financeira a todo custo, está gerando um desiquilíbrio na ordem natural do nosso planeta, onde o próprio ser humano passa a desconhecer e respeitar o seu semelhante. Como dito por Boff (2004, p. 23):

Hoje a Terra se encontra em fase avançada de exaustão e o trabalho e a criatividade, por causa da revolução tecnológica, da informatização e da robotização, são dispensados e os trabalhadores excluídos até do exército de reserva do trabalho explorado. Ambos, terra e trabalhador, estão feridos e sangram perigosamente.

Ainda que a intenção seja continuar promovendo o desenvolvimento das nações, especialmente das ditas ricas e desenvolvidas, sabe-se que o padrão produtivo e de consumo dessas nações não poderiam ser copiados por todos os países, sob a pena de se exaurir rapidamente as reservas naturais ainda existentes. Nesse sentido, tanto a viabilidade econômica quanto a ecológica tem de ser levado em conta, especialmente num mundo onde há muito desperdício, partilha desigual de bens e recursos e falta de comprometimento com as gerações futuras. Sabemos que desenvolver um trabalho que envolva o espaço global, com resultados imediatos é utopia, no entanto, pensar o local e desenvolver práticas nesse espaço pode se transformar numa opção que venha contribuir para um novo pensar sobre a relação homem-natureza.

Para tanto é fundamental que haja respeito às particularidades de cada comunidade, além de promover um fazer consciente e transformador, comprometido com o coletivo. Sociedades que possuem verdadeiras ações 
voltadas para as questões ambientais, normalmente possuem na educação a sua grande aliada nesse processo, pois todo verdadeiro processo educacional traz em sua própria essência o respeito às diferenças, o caminho em direção do bem societário, discussões entre seus pares e a busca por transformações que culminem com o equilíbrio socioambiental.

Para Mayer (1998), o entendimento da problemática envolvendo meio ambiente e qualidade de vida passa pelo processo educativo, pois a falta de conhecimentos emperra a busca por possíveis soluções. Quando se analisa esse viés de entendimento com mercado produtivo, consumo desenfreado, degradação ambiental e o desconhecimento dessa correlação, percebe-se que a apropriação dos recursos naturais deveria ser acompanhada por uma prática educacional que venha vislumbrar caminhos alternativos com a intenção da transformação do ser humano, a qual o sensibilize a pôr em prática o altruísmo e o bem-estar coletivo.

Nesse sentido, o caminho pensado por Karl Marx, através do materialismo histórico, pode ser encarado como uma alternativa junto a essa realidade, pois o mesmo preconiza o resgate do ser humano em função de interferências e sua formação histórica, almejando assim uma maior compreensão do seu papel enquanto cidadão dentro de sua comunidade. Isso possibilitaria a sua instrumentalização para a apropriação dos recursos naturais de forma mais racional através do seu trabalho, respeitando a necessidade de sobrevivência das futuras gerações e do funcionamento dos diversos ecossistemas.

A chamada sustentabilidade ambiental, portanto, é algo que suscita muita discussão, pois a sua compreensão deve ser analisada de forma contextualizada e não apenas a partir de um viés econômico e estanque como muitos procuram sustentar para a sua prática. Nesse sentido, nos diz Loureiro (2012, p. 56):

No âmbito do debate sobre sustentabilidade, necessidades são vistas tanto no sentido material quanto simbólico - portanto, econômico e cultural. Assim, fazem parte destas: subsistência (garantindo a existência biológica); proteção; afeto; criação; produção; reprodução biológica, participação na vida social, identidade e liberdade. Portanto, sustentável não é o processo que apenas se preocupa com uma das duas dimensões, mas que precisa contemplar ambas, o que é um enorme desafio diante de uma sociedade que prima pelos interesses econômicos acima dos demais.

Podemos verificar que o conceito de desenvolvimento sustentável é bastante complexo e desafiador, especialmente pelo fato de envolver os mais variados elementos pertinentes ao bem-estar da sociedade e, ao mesmo tempo, interferir nos interesses de diversas classes sociais. No entanto, uma coisa é certa: sem transformar e sensibilizar o ser humano isso estará fadado ao insucesso. O homem tem que se sentir novamente integrante desse grande organismo chamado Terra e perceber que o seu papel é fundamental para que o 
equilíbrio de todos os ecossistemas ocorra. Fato que merece destaque dentro desse raciocínio é a preocupação que as gerações atuais devam ter para com a de seus filhos, pois como dito por Maturana (2008), uma criança que cresce no respeito por si mesma, pode aprender qualquer coisa e adquirir qualquer habilidade se o desejar. Por tanto, a verdadeira sustentabilidade está diretamente relacionada ao respeito pelo próximo, por uma melhor distribuição dos recursos naturais, pelo combate ao desperdício e a busca por uma sociedade mais solidária, a qual acabe por adquirir a capacidade de enxergar a sua felicidade plena como produto da felicidade de seus pares e do equilíbrio planetário.

\section{Considerações finais}

$\mathrm{Na}$ busca por sua subsistência, historicamente a humanidade sempre foi movida pela necessidade de encontrar melhores condições que satisfizessem 0 seu bem-estar e de sua família, fato que até a primeira metade do século XIX gerava impactos menores sobre a natureza. A partir desse momento, quando 0 sistema capitalista passou de sua fase concorrencial para a fase monopolista e/ou oligopolista, os sistemas produtivos foram aprimorados e o excedente de produção passou a ser necessário, pois seria a garantia da concentração de riquezas. Isso gerou uma escalada crescente junto ao consumo de recursos naturais disponíveis, calcado numa ideologia em que a oferta de manufaturas seria infinita e ao alcance de todos, estimulado especialmente pela mídia. Hoje sabemos que o sistema produtivo dominante no planeta vem apresentando indícios claros de que essa realidade é uma falácia, já que uma minoria de países continua se reciclando no poder há séculos e a ideia de que os países subdesenvolvidos hoje serão os desenvolvidos de amanhã, engrossa um enredo mentiroso, meticulosamente planejado por uma minoria que pretende continuar se reciclando no poder.

Entender o ser humano em sua formação histórica é condição ímpar para que se possamos encontrar caminhos que contribuam decisivamente para a sua transformação em cidadão reflexivo, crítico, criativo e participativo em sua sociedade, condições fundamentais para se romper com velhos paradigmas. $O$ ser humano sofre forte influência do meio ao qual cresce, portanto, a sua capacidade egoísta e a intenção de prejudicar o próximo normalmente nascem de um meio onde o respeito e o altruísmo são práticas incomuns. Como dito por Ferrari (2003), quando assumimos a dimensão do cuidado em nossas vidas, vivemos verdadeiramente a experiência do valor que não nos permite agir utilitariamente ou egoisticamente. Portanto, tentar mudar velhos conceitos que já são encarados como tradicionais não é tarefa fácil, especialmente quando a sociedade atual, talvez até por comodismo, não queira abdicar das ditas benesses ofertadas pelo sistema atual. Para tanto, um novo pensar educativo se faz necessário, onde a prática de uma nova relação ensino-aprendizagem, que objetive uma participação mais consciente do cidadão no contexto societário, questionando comportamentos, atitudes e valores, certamente proporcionarão gerações diferentes. 
Segundo Loureiro (2011), a cidadania se constitui ao dar significado ao pertencimento do indivíduo a uma sociedade, em cada fase histórica. Dessa forma, criar condições para que o ser humano se veja como integrante de sua sociedade é condição ímpar que o mesmo se sinta na responsabilidade de lutar por um espaço cada vez melhor para si e para os seus pares. Dessa forma a sociedade começará a possuir um sentido de organização que a possibilite enxergar e exigir os seus direitos, além de sua participação efetiva nas decisões políticas que, na maioria das vezes, ocorrem sem seu conhecimento. Ao longo da evolução do sistema político vigente, o ser humano foi sendo isolado e afastado de suas prerrogativas enquanto cidadão, onde os deveres passaram a se destacar perante os seus direitos, estratégia que serviu durante muito tempo para se enfraquecer o poder de organização e de cobrança das mais variadas classes sociais. O homem atual, em função dos meios de comunicação e de transportes, mantém um contato permanente com as mais variadas localidades e pessoas, o que vem possibilitando a troca de informações sobre a problemática ambiental vigente. O entendimento de que algo precisa ser feito, somado a necessidade de se buscar mudanças no comportamento humano, parece ser o caminho mais objetivo no momento, onde a educação possui papel destacado para tais transformações.

Buscar soluções puramente imediatistas, sem consistência e que não se sustentaria ao longo dos tempos poderia se transformar em mais uma falácia, o que acabaria por cair em descrédito e interessar apenas aquela fatia da sociedade que vem fazendo a sua manutenção no poder. Nesse contexto se torna fácil entender o negligenciamento da educação durante a formação histórica de diversos grupos sociais. A sua verdadeira prática, que reside no fato de se tornar capaz de gerar condições para a formação ética do ser humano, promovendo a sua transformação e participação crítica, dialógica e criativa dentro do seu convívio social, certamente não seria coerente para o sistema vigente. Como apontado por Loureiro (2013, p. 65):

É a própria práxis educativa, a indissociabilidade teoria-prática na atividade humana consciente de transformação do mundo e de autotransformação que ganha a devida centralidade. Isso explica favorecer a contínua reflexão das condições de vida, na prática concreta, como parte inerente do processo social e como elemento indispensável para a promoção de novas atitudes e relações que estruturam a sociedade.

Diante do exposto, acreditamos que seja tanto possível trilhar outros caminhos que contribuam para um melhor entendimento da crise ambiental que se faz presente, como a busca por soluções. Se o ser humano teve a capacidade de gerar esse quadro, também possui o dever ético e moral de tentar mudá-lo, pois as gerações futuras não podem pagar por algo que não tiveram participação. Nesse sentido, não adianta pura e simplesmente ficar buscando agora os verdadeiros culpados por tudo isso, até pelo fato de que muitos já se foram e que, cada um ao seu jeito, possui alguma participação 
nesse processo, seja por ação ou omissão. Boff (2004) nos diz que a consciência é a forma mais alta de vida. Portanto, criar condições verdadeiras para que o ser humano possa crescer em meio a um ambiente respeitoso, salubre e que lhe possa garantir o seu sustento não é utopia, mas uma necessidade para que possamos construir um mundo melhor.

\section{Referências}

BENYUS, J.M. Biomimicry: innovation inspired by Nature. In: LAYRARGUES, P. P. Para onde vai a Educação Ambiental? O cenário político-ideológico da Educação Ambiental brasileira e os desafios de uma agenda política crítica contrahegemônica. Revista Contemporânea de Educação, v. 7, 398-421, 2012.

BOFF, L. Ecologia: Grito da Terra Grito dos Pobres. Rio de Janeiro: Sextante, 2004, 319 p.

CISE, P. O marxismo e o "desenvolvimento sustentável". In: LAMBERT, P. O ecologismo contra a ecologia. São Paulo: A Verdade, Revista teórica da quarta internacional, 2008. P. 23-45.

DEMO, P. Participação é conquista. São Paulo: Cortez, 1988.

FERRARI, A.R. A responsabilidade como princípio para uma ética da relação entre ser humano e natureza. Rev. Eletrônica Mestr. Educ. Amb.. v. 0, p. 76-88, 2003.

FREIRE, P. A pedagogia histórico-crítica: primeiras aproximações. In: LOUREIRO, C. F. B. et al. Contribuições da teoria marxista para a Educação Ambiental crítica. Campinas: Cad. Cedes, 2009. p. 81-97.

GUIMARÃES, M. Armadilha paradigmática na Educação Ambiental. In: LOUREIRO, C.F.B. et al. Pensamento complexo, dialética e Educação Ambiental. São Paulo: Cortez, 2011. P. 15-29.

HOBSBAWM, E.J. Era dos Extremos: o breve século XX: 1914-1991. 46. ed. São Paulo: Companhia das Letras, 2012.

INFOMONEY, E. A história da Black Monday, o maior tombo da história das bolsas. Disponível em: www.infomoney.com.br/mercados/noticia Acesso em 31 jan. 2014.

JACOBI, P. Educação Ambiental, cidadania e sustentabilidade. Cadernos de Pesquisa, n.118, p. 189-205, 2003.

JACOBI, P. Educação Ambiental: o desafio da construção de um pensamento crítico, complexo e reflexivo. Educação e Pesquisa, v. 31, p. 233-250, 2005.

LAYRARGUES, P.P. Muito além da natureza: Educação Ambiental e reprodução social. In: LOUREIRO, C.F.B. et al. Pensamento complexo, dialética e Educação Ambiental. São Paulo: Cortez, 2011. P. 72-103.

LAYRARGUES, P.P. Para onde vai a Educação Ambiental? O cenário políticoideológico da Educação Ambiental brasileira e os desafios de uma agenda política crítica contra-hegemônica. Revista Contemporânea de Educação, vol. 7, n. 14, p. 398-421, 2012. 
LAYRARGUES, P.P.; LIMA, G.F.C. Mapeando as macrotendências políticopedagógicas da Educação Ambiental contemporânea no Brasil. In: LAYRARGUES, P.P.; Para onde vai a Educação Ambiental? O cenário político-ideológico da Educação Ambiental brasileira e os desafios de uma agenda política crítica contra-hegemônica. Brasília: Revista Contemporânea de Educação, vol. 7, 2012. p. 398-421.

LEFF, E. Saber ambiental: sustentabilidade, racionalidade, complexidade, poder. 2. Ed. Petrópolis: Vozes, 2001. In: LOUREIRO, C.F.B, et.al. Contribuições da teoria marxista para a Educação Ambiental crítica. Cad. Cedes, Campinas, vol. 29, n. 77, p. 81-97, 2009.

LEROY, J.P; PACHECO, T. Dilemas de uma educação em tempo de crise. In: LOUREIRO, C.F.B. et al. Pensamento complexo, dialética e Educação Ambiental. São Paulo: Cortez, 2011. P. 30-71.

LIMA, G.F.C.; Educação Ambiental crítica: do socioambientalismo às sociedades sustentáveis. Educação e Pesquisa, v. 35, n. 1, p. 145-163, 2009.

LIMA, G.F.C. O debate da sustentabilidade na sociedade insustentável. "Política \&Trabalho", n. 13, p. 201-222, PPGS/UFPB, 1997.

LOUREIRO, C.F.B. Educação Ambiental e movimentos sociais na construção da cidadania ecológica e planetária. In: LOUREIRO, C.F.B.; LAYRARGUES, P.P.; CASTRO, R. S. (Org.). Educação ambiental: repensando o espaço da cidadania. 2. ed. São Paulo: Cortez, 2011. p. 69-98.

LOUREIRO, C.F.B. Sustentabilidade e educação. São Paulo: Cortez, 2012, 128p.

LOUREIRO, C.F.B.; LAYRARGUES, P. P. Ecologia política, justiça e Educação Ambiental crítica: perspectivas de aliança contra-hegemônica, v. 11, n. 1, p. 53-71, 2013.

LOUREIRO, C.F.B.; TREIN, E; TOZONI-REIS, M.F.C; NOVICKI, V. Contribuições da teoria marxista para a Educação Ambiental crítica. Cad. Cedes, vol. 29, p. 81-97, 2009.

LOUREIRO, C.F.B.; VIÉGAS, A. Diálogos entre a tradição dialética marxiana e a complexidade em Morin: contribuições para a Educação Ambiental. In: LOUREIRO, C.F.B.; VIÉGAS, A. Algumas considerações sobre as influências do marxismo na teoria da complexidade de Edgar Morin: aportes para a pesquisa em Educação Ambiental. Ambiente \& Educação, v. 17, n. 2, p.13-24, 2012.

MAYER, M. Educación Ambiental: de la acción a la investigación. Enseñanza de las Ciencias, v. 16, n. 2, jun. 1998.

MARTINEZ-ALIER, J. O ecologismo dos pobres: conflitos ambientais e linguagens de valoraçõa. In: LAYRARGUES, P. P. Para onde vai a Educação Ambiental? O cenário político-ideológico da Educação Ambiental brasileira e os desafios de uma agenda política crítica contra-hegemônica. Revista Contemporânea de Educação, v. 7, 398-421, 2012.

MARX, K. El capital. Tomo III, v. 8. México: Siglo XXI. [1894] 1981.

MARX, K. Manuscritos econômicos e filosóficos. In: TREIN, E.S.; A Educação Ambiental crítica: crítica de que? Revista Contemporânea, 2012. p. 304-318. 
MARX, K. Manuscritos econômicos-filosóficos. São paulo: Boitempo, 2004.

MARX, K.; ENGELS, F. A Ideologia Alemã. In: LOUREIRO, C.F.B. et al. Contribuição da teoria marxista para a Educação Ambiental crítica. Campinas: Cad. Cedes, 2009. P. 81-97.

MATURANA, H.; VERDEN-ZÖLLER,G. Amar é brincar: fundamentos esquecidos do humano. São Paulo: Palas Athena, 2004.

MÉSZÁROS, I. A educação para além do capital. São Paulo: Boitempo, 2005.

NOVELLI, P.G.A., PIRES, M.F.C. A dialética na sala de aula. Botucatu: UNESP, 1996.

PIRES, M.F.C. O materialismo histórico-dialético e a educação. Texto apresentado na mesa-redonda "Paradigmas de Interpretação da Realidade e Projetos Pedagógicos", organizada pelas disciplinas de Pedagogia Médica e Didática Especial dos Cursos de Pós-graduação da Faculdade de Medicina da UNESP, p. 83-94, 1997.

RESOURCES, W. A repor by the World Resources Institute and the International Institute for Enviroment and Development, 1986, p. 47 e 142. Disponível em:<www.wri.org/publication/world-resources-1986> Acesso: 20/02/14.

SACHS, I.; LOPES, C.; DOWBOR, L. Crises e oportunidades em tempos de mudança. Economia Global e Gestão. 2010, vol.15, n.1, pp. 133-154.

SAUVÉ, L. Uma cartografia das correntes em Educação Ambiental. In: SATO, M; CARVALHO, I.C.M; Educação Ambiental: pesquisa e desafios. Porto Alegre: Artmed, 2005. P.17-44.

SAVIANI, D. A pedagogia histórico-crítica: primeiras aproximações. 9. ed. Campinas: Autores Associados, 2005.

TOZONI-REIS, M.F.C. Educação Ambiental: natureza, razão e história. In: LAYRARGUES, P.P. Para onde vai a Educação Ambiental? O cenário políticoideológico da Educação Ambiental brasileira e os desafios de uma agenda política crítica contra-hegemônica. Revista Contemporânea de Educação, v. 7, 398-421, 2012.

TREIN, E. S. A Educação Ambiental crítica: Crítica de que? Revista Contemporânea de Educação, n. 14, p. 304-318, 2012. 